\title{
Multiresidue Determination of Pesticides in Drinking Water by Gas Chromatography-Mass Spectrometry after Solid-Phase Extraction
}

\author{
Guilherme P. Sabin, Osmar D. Prestes, Martha B. Adaime and Renato Zanella* \\ Departamento de Química, Universidade Federal de Santa Maria, 97105-900 Santa Maria-RS, Brazil
}

\begin{abstract}
Neste trabalho, um método usando extração em fase sólida e cromatografia a gás acoplada à espectrometria de massas no modo de monitoramento seletivo de íons, foi desenvolvido e validado para a determinação multiclasse de 20 pesticidas regulados pela legislação brasileira para água potável. Como estes pesticidas devem ser determinados em baixas concentrações, um elevado fator da pré-concentração associado à sensibilidade elevada da análise cromatográfica foi necessário. O método apresentou limites de quantificação entre 0,003 e $0,093 \mu \mathrm{g} \mathrm{L} \mathrm{L}^{-1}$. A maioria dos compostos apresentou recuperações médias entre 51 e $116 \%$. Embora a natureza química distinta dos pesticidas analisados dificulte a obtenção de boa recuperação para todos os compostos avaliados, a precisão dos resultados foi excelente. A seletividade do método foi avaliada através da intensidade relativa dos íons de quantificação e de qualificação, sendo considerada adequada. A análise em amostras reais cumpriu os critérios para a qualificação instrumental e a avaliação da conformidade do sistema.
\end{abstract}

In this work, a method using solid-phase extraction and gas chromatography coupled mass spectrometry in the selective ion monitoring (SIM) mode was developed and validated for the multi-class determination of 20 pesticides regulated by the Brazilian legislation for drinking water. Because these pesticides must be determined at low concentrations, a high preconcentration factor associated to the high sensitivity of chromatographic analysis was necessary. The method presented quantification limits between 0.003 and $0.093 \mu \mathrm{g} \mathrm{\textrm {L } ^ { - 1 }}$. Most of the compounds presented mean recoveries between 51 and $116 \%$. Although the differing chemical nature of the pesticides analyzed difficult the attainment of good recovery for all of the compounds evaluated, the precision of the results was excellent. The selectivity of the method was evaluated through the relative intensity of quantification and qualification ions and was considered adequate. Analysis in real samples met criteria for instrumental qualification and the system suitability evaluation.

Keywords: solid-phase extraction, GC-MS, pesticide, multiresidue, water

\section{Introduction}

Although pesticides increase agricultural productivity, their use can produce serious environmental problems through the contamination of water resources. Therefore, legal limits and alert levels for drinking water have been introduced. ${ }^{1}$ In Brazil, the Ministry of Health, through Regulation MS 518 of March 25, 2004 established procedures and requirements for the control and vigilance of water quality for human consumption and drinking water standards, including limits for some pesticide residues. ${ }^{2}$ The European Union (EU) Directive on the quality of drinking water has set the maximum admissible concentrations of each pesticide at $0.1 \mu \mathrm{g} \mathrm{L}^{-1}$, and the total concentration of

*e-mail: rzanella@base.ufsm.br all pesticides at $0.5 \mu \mathrm{g} \mathrm{L}{ }^{-1}{ }^{3}$ The WHO threshold values for concentrations of pesticides in drinking water, based on toxicological considerations, are less strict than the maximum concentrations allowed by EU. ${ }^{1}$

Although the importance of the determination of pesticide residues in drinking water, only few works with samples from Brazil were published and most studies were focused on a limited scope like organochlorine pesticides ${ }^{4,5}$ and triazine herbicides. ${ }^{6,7}$

In this work, pesticides were chosen based on their necessity for regulation in water for human consumption as established by current Brazilian legislation. The pesticides selected (Figure 1) present quite distinct physicochemical and chromatographic characteristics.

The physicochemical properties of pesticides can be used as a criterion in the evaluation of risk to the aquatic 
<smiles>CCc1cccc(CC)c1N(COC)C(=O)OCCl</smiles>

alachlor $(\mathrm{H})$<smiles>ClC1=C(Cl)C2(Cl)C3C4C=CC(C4Cl)C3C1(Cl)C2(Cl)Cl</smiles>

aldrin (I)

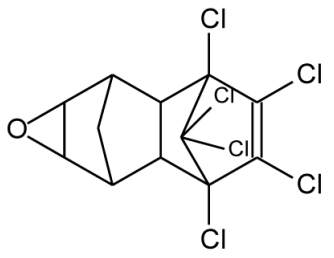

dieldrin (I)<smiles>CCNc1nc(Cl)nc(NCC)n1</smiles>

atrazine $(\mathrm{H})$<smiles>CCn1c(=O)[nH]c2ccccc2c1=O</smiles>

bentazone $(\mathrm{H})$<smiles>CC1CC2C(Cl)C(Cl)C3(Cl)C(Cl)=C(Cl)C4(Cl)C2(Cl)C1(Cl)C4(Cl)C3(Cl)Cl</smiles>

heptachlor (I)<smiles>ClC1=C(Cl)C2(Cl)C3C4OC4C(Cl)C3C1(Cl)C2(Cl)Cl</smiles>

heptachlor-epoxide (I)<smiles>ClC1=C(Cl)C2(Cl)C3(Cl)CO[GeH]4OCC3C1(Cl)C2(Cl)C4Cl</smiles>

endosulfan (I)<smiles>ClC1=C(Cl)C2(Cl)C3C4CC(C5COC54)C3C1(Cl)C2(Cl)Cl</smiles>

endrin (I)<smiles>CCc1ccccc1N(C(=O)Cl)C(C)COC</smiles>
metolachlor $(\mathrm{H})$<smiles>COc1ccc(C(c2ccc(OC)cc2)C(Cl)(Cl)Cl)cc1</smiles>

methoxichlor (I)<smiles>Clc1c(Cl)c(Cl)c(Cl)c(Cl)c1Cl</smiles>

hexachlorbenzene (F,I)<smiles>ClC1C(Cl)C(Cl)C(Cl)C(Cl)C1Cl</smiles>

lindane (I)<smiles>CCC(C)Nc1c([N+](=O)[O-])cc(C)c(C)c1[N+](=O)[O-]</smiles>

pendimethalin $(\mathrm{H})$<smiles>CCOC(=O)Nc1ccc(Cl)c(Cl)c1</smiles>

propanil $(\mathrm{H})$<smiles>CCNc1nc(Cl)nc(NCC)n1</smiles>

simazine $(H)$<smiles>CC1(C)C(C=C(Cl)Cl)C1C(=O)OCc1cccc(Oc2ccccc2)c1</smiles>

permethrin (I)<smiles>CCCNc1c([N+](=O)[O-])cc(C(F)(F)F)cc1[N+](=O)[O-]</smiles>

trifluraline $(\mathrm{H})$

Figure 1. Structure of selected pesticides ( $\mathrm{H}=$ Herbicides; $\mathrm{I}=$ Insecticides; $\mathrm{F}$ = Fungicides). 
environmental, ${ }^{8}$ but they also provide important information as to behavior during the stages of preconcentration, solvent evaporation, stability in water and adsorption on organic material present in the samples. For chromatographic determination it is necessary to investigate the analytes' physicochemical properties to achieve high selectivity and sensitivity. Sample preparation is the first step to develop a good analytical method. The literature has shown excellent advantages of using solid-phase extraction for multiresidue pesticide analysis in water, including shorter analysis times, low solvent consumption, high preconcentration factor, good recoveries and precisions, applicability in a wide range of polarities and selective extractions. ${ }^{9-11}$ Huck and Bonn ${ }^{12}$ reported solid-phase extraction with polymericbased sorbents with better results than those obtained with C-18. Pichon et al. ${ }^{13}$ described the difficulty of working with analytes with a wide range of polarities, underlining the problems of elution and strong retentions.

For the determination of relatively volatile and thermally stable apolar or medium polarity compounds, GC-MS has given excellent results, especially simultaneous determinations of compounds with differing classes and properties. ${ }^{11,14}$ The advantages of GC-MS in SIM mode, including high sensitivity, selectivity and robustness, have been pointed out by several authors. ${ }^{15,16}$

Therefore, this study aims to develop and validate a reliable, highly sensitive, low-cost method with a short analysis time. The method, based on solid-phase extraction and quantification by gas chromatography coupled to mass spectrometry (GC-MS) in the selective ion monitoring (SIM) mode was validated for a number of parameters including system suitability for routine analysis.

\section{Experimental}

\section{Standards, reagents and solvents}

Analytical standards of the pesticides evaluated (purity between 94.0 and 99.7\%) were acquired from Dr. Ehrenstorfer (Augsburg, Germany). The internal standard, 1,3-diphenoxybenzene, was provided by SigmaAldrich (Poole, United Kingdom). Surrogate standards, 1,4-dichlorobenzene-d4, naftalene-d8, acenaftene-d10, antracene-d10, crisene-d12 and perilene-d12, were obtained from Chem Service (West Chester, USA). Working standard solutions were prepared in ethyl acetate.

Pesticide grade/analytical reagent grade ethyl acetate, dichloromethane and methanol were purchased from JT Baker (Phillipsburg, USA). Milli-Q purified water was obtained from Millipore (St. Quentin-in-Yvelines, France) and helium 99.999\% was obtained from AGA (Barueri-
SP, Brazil). The following SPE cartridges were used for compound preconcentration: Strata-X ${ }^{\circledR} 30 \mathrm{mg}$ per $3 \mathrm{~mL}$ (Phenomenex, Torrance, USA), Nexus ${ }^{\circledR} 60 \mathrm{mg}$ per $3 \mathrm{~mL}$ (Varian, Palo Alto, USA), Oasis ${ }^{\circledR} 30 \mathrm{mg}$ per $3 \mathrm{~mL}$ (Waters, Milford, USA) and C18 $500 \mathrm{mg}$ per $6 \mathrm{~mL}$ (Phenomenex, Torrance, USA).

\section{Apparatus}

Determination was performed using an Agilent GC system (model HP 6890N) equipped with a split/splitless injector, liner of silanized quartz with $4 \mathrm{~mm}$ i.d. (effective volume $0.49 \mathrm{~mL}$ ), and a 7683 autosampler for 100 vials (Wilmington, EUA). Chromatographic conditions were: HP5-MS low bleed capillary column $(30 \mathrm{~m} \times 0.25 \mathrm{~mm}$ i.d. $\times$ $0.25 \mu \mathrm{m}$ film thickness); helium was used as a gas carrier; flow constant: $1.0 \mathrm{~mL} \mathrm{~min}{ }^{-1}$; injection volume: $2 \mu \mathrm{L}$ (pulsed splitless: 15 psi for $1.5 \mathrm{~min}$ ); injector temperature $250{ }^{\circ} \mathrm{C}$; GC temperature program: $50^{\circ} \mathrm{C}(2 \mathrm{~min}), 30^{\circ} \mathrm{C} \mathrm{min}^{-1}$ up to $160{ }^{\circ} \mathrm{C}(5 \mathrm{~min}), 5^{\circ} \mathrm{C} \mathrm{min}{ }^{-1}$ up to $180{ }^{\circ} \mathrm{C}$ and $10{ }^{\circ} \mathrm{C} \min ^{-1}$ up to $270{ }^{\circ} \mathrm{C}$ (6 min). A HP 5973N Agilent quadrupole mass spectrometer (Palo Alto, EUA) was operated in selective ion monitoring (SIM) mode, with ionization source by electron impact at $70 \mathrm{eV}$, transfer line at $280^{\circ} \mathrm{C}$, ion source at $230{ }^{\circ} \mathrm{C}$ and quadrupole at $150{ }^{\circ} \mathrm{C}$.

In the SPE sample preparation stage, a manifold system with capacity for 12 cartridges (Phenomenex; Torrance, USA) and a vacuum pump (model TE-058, Tecnal; Piracicaba, Brazil) were used.

\section{Chromatographic separation and ion selection}

To determine the best temperature program, a retention time behavioral study was performed for all compounds, based on which, a multi-linear temperature program was adopted.

Selective ion monitoring (SIM) mode was utilized in order to achieve high selectivity and sensitivity. One ion was chosen for quantification and another for qualification, based on the best signal-noise ratios and the highest masses.

\section{SPE preconcentration}

Initially, the retention capacity results obtained for the sorbents Strata- $\mathrm{X}^{\circledR}, \mathrm{Nexus}^{\circledR}$, Oasis ${ }^{\circledR}$ and C18 were evaluated. Ethyl acetate and dichloromethane were tested as elution solvents. The following SPE steps were performed: (i) Conditioning: each cartridge was conditioned with two cartridge volumes of methanol and two volumes of purified water, avoiding drying of the sorbent; (ii) percolation of the sample: $200 \mathrm{~mL}$ of each sample, after adding the surrogate standards, were percolated at approximately $2 \mathrm{~mL} \mathrm{~min}{ }^{-1}$. 
Then, the cartridges were washed with a cartridge volume of purified water and dried for $30 \mathrm{~min}$ in the manifold system under vacuum; (iii) elution and redissolution: the analytes were eluted with $2 \mathrm{~mL}$ solvent in two steps $(1+1 \mathrm{~mL})$, with an interaction time of $1 \mathrm{~min}$ for each step. The solvent was removed by drying in water bath at $55^{\circ} \mathrm{C}$ for approximately 20 minutes. The analytes were redissolved by adding $0.5 \mathrm{~mL}$ of the redissolution solution containing the internal standard in ethyl acetate.

\section{Method validation and quality assurance}

Analytical curves were established by injecting 7 times each analytical solution containing the pesticides at concentrations between 1 and $1000 \mu \mathrm{g} \mathrm{L}^{-1}$. Linear regression and polynomial equations were generated as a model of prediction. Internal standardization was adopted and application range was defined based on method linearity, quantification limits and maximum limits allowed in drinking water by Brazilian legislation.

Method selectivity was ensured by using SIM and by the absence of quantification and qualification ions in analyte retention time of a blank sample. In real samples, selectivity was ensured by the ratio between quantification and qualification ions with a tolerance of $20 \%$. This tolerance can be increased to $30 \%$ close to the quantification limit. ${ }^{11}$

The limits of detection (LOD) and of quantification (LOQ) were established from the signal-noise ratio of quantification ions and qualification ions selected for each compound studied. Seven injections of the standard solution $10 \mu \mathrm{g} \mathrm{L}^{-1}$ were performed, with the exception of chlordane, DDT and permethrin which are isomeric mixtures considered individually as fractions proportional to the peak heights of their respective isomers. Concentration levels near to the estimated quantification limits were chosen. The mean results for peak height were used for the coefficient of sensitivity calculation, which convert the signal into the concentration. The blank sample was injected 7 times. Mean standard deviation from the noise was determined. The lowest noise was established as its own unit due to the high signal stability in SIM mode, which presented lower deviation for all compounds than the unit of abundance. The LOD was established as the concentration where the ion of lowest abundance presented a peak height corresponding to 3 times the signal-noise ratio. For the LOQ, 10 times the signal-noise ratio was considered for quantification ions, as long as the qualification ion was at least 6 times this ratio. Therefore, both limits are guaranteed in a confirmatory way. ${ }^{17}$

Instrumental precision was evaluated from the results of 7 replicates for each concentration of the linearity study. Relative standard deviation (RSD) was compared with the Horwitz curve. ${ }^{18}$ To evaluate the accuracy and precision of the method in terms of repeatability and intermediate precision, blank samples were fortified at three different concentration levels $0.030,0.100$ and $0.300 \mu \mathrm{g} \mathrm{L} \mathrm{L}^{-1}$, identified as F1, F2 and F3, respectively. These concentrations represent $1,3.3$ and 10 times the lowest limits established by Brazilian legislation for drinking water and allowed the evaluation of accuracy, in terms of recovery, and precision of the proposed method. Intermediate precision was evaluated in order to simulate a more real routine analysis situation, and was determined by six repetitions of the complete procedure using the same three concentration levels on three different days.

For routine assays, certain parameters should be periodically verified to guarantee system suitability and validity of results. The parameters chosen for this purpose were: peak area and retention time of the internal standard, efficiency, sensitivity, coefficient of determination, recovery of surrogate standards and selectivity. However, the detection of very low levels may not always be essential and it may be acceptable in some circumstances to define a practical reporting limit based on the proposed use of the analytical data. ${ }^{19,20}$ This would have the advantage of reducing the technical difficulty of obtaining data and of reducing costs.

\section{Application in real samples}

The method was tested with 5 real samples with different characteristics: two samples of untreated water (water from superficial springs and wells) and three samples of water treated at water treatment facilities (water from creeks, rivers and lakes). The purpose was to include samples with different characteristics and differing levels of mineral salts, $\mathrm{pH}$, turbidity, fulvic and humic acids, among other features. Samples were collected in glass recipients and stored in a dark place at temperatures between 1 and $4{ }^{\circ} \mathrm{C}$.

\section{Results and Discussion}

\section{Chromatographic system}

The chromatogram in Figure 2 shows the good separation obtained after the retention time and oven temperature studies.

The optimization of the chromatographic analysis by ideal gas law application allowed a better chromatographic response and, therefore, a 4-fold reduction of the preconcentration factor in the sample preparation, which reduces extraction time. 


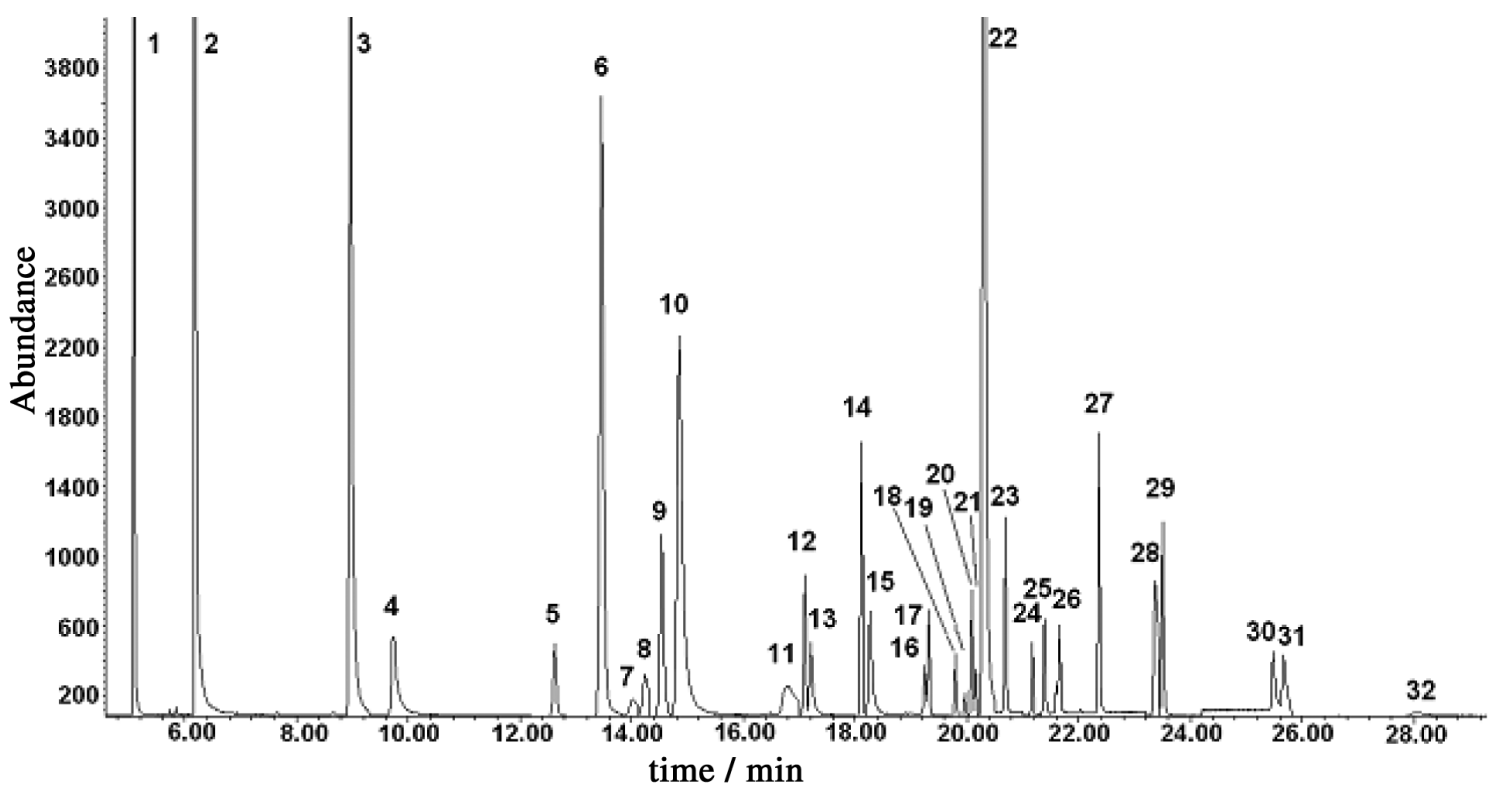

Figure 2. Typical chromatogram of a blank water sample fortified at $0.300 \mu \mathrm{g} \mathrm{L}^{-1}$. Compound identification is shown in Table 1 .

\section{SPE preconcentration}

The polymeric sorbents Strata- $\mathrm{X}^{\circledR}(30 \mathrm{mg}$ per $3 \mathrm{~mL})$ presented consistent good recoveries for the most of the studied pesticides and it was chosen for this method. Dichloromethane presented best results than ethyl acetate as eluent. The analytes were eluted with $2 \mathrm{~mL}$ dichloromethane in two aliquots of $1 \mathrm{~mL}$ and an interaction time of $1 \mathrm{~min}$ for each step. Dichloromethane is more volatile than ethyl acetate and permitted an easier evaporation step before GC-MS analysis.

\section{Method validation}

Method selectivity was shown to be adequate for the determination of the pesticide studies. Table 1 shows percentual difference between the recovery obtained for the quantification ion and the qualification ion of each compound. Maximum tolerance was $20 \%$ for levels F2 and F3 and 30\% for level F1 and should be evaluated critically for each case. ${ }^{11}$

Although lindane had a systematic matrix effect on the qualification ion, it had a maximum residue limit (MRL) of $2 \mu \mathrm{g} \mathrm{L} \mathrm{L}^{-1}$ making the matrix effect negligible. Molinate and permethrin also had a matrix effect on the qualification ion, but only for F1, which does not denote a problem for determinations with MRLs near 6 and $20 \mu \mathrm{g} \mathrm{L}^{-1}$, respectively.

Most of the pesticides presented $r^{2}$ values greater than 0.99. Alachlor, atrazine, metolachlor, permethrin, propanil and simazine presented $r^{2}$ values of $0.98,0.97,0.98,0.98$,
0.97 and 0.97 , respectively. When polynomial equations were used a minimum $\mathrm{r}^{2}$ of 0.9997 was verified. In the range studied, linearity was adequate for all compounds. However, for routine analyses a curve of three levels (12, 40 and $120 \mu \mathrm{g} \mathrm{L}^{-1}$ ), which correspond to the concentrations in water of $0.030,0.100$ and $0.300 \mu \mathrm{g} \mathrm{L}^{-1}$, was used in order to prioritize the best quantification of lower concentration levels. When concentrations above the working range are verified, a dilution of the extract for quantification should be performed.

Results for instrumental precision are shown in Table 2. RSD values that meet Horwitz curve criteria are shown in the shaded area of Table 2. It is important to note that the lowest concentration level with acceptable precision is lower than $50 \%$ of the MRL, rendering instrumental precision adequate. Repeatability, intermediate precision and method recovery can be seen in Table 3 . According to the Horwitz curve, for the concentration level of $0.030 \mu \mathrm{g} \mathrm{L}^{-1}$, the adequate RSD for repeatability ( $\mathrm{RSD}_{\mathrm{r}}$ ) is $38 \%$ and adequate RSD for intermediate precision $\left(\mathrm{RSD}_{\mathrm{pi}}\right)$ is $76 \%$. For the concentration level of $0.300 \mu \mathrm{g} \mathrm{L}^{-1}$, adequate $\mathrm{RSD}_{\mathrm{r}}$ is $27 \%$ and $\mathrm{RSD}_{\mathrm{pi}}$ is $54 \%$.

The results in bold type refer to compounds with MRL values at the F1 concentration level. Precision results were considered excellent. The other compounds were evaluated by the F3 concentration level as they presented MRLs over $0.300 \mu \mathrm{g} \mathrm{L}{ }^{-1}$. Method precision was considered excellent. Recoveries for each compound at the three fortification levels were very consistent. Hexachlorobenzene, aldrin, DDT and permethrin presented low recoveries.

All the pesticides presented signals greater than their 
Table 1. Percentual difference between the recoveries obtained for the quantification ion and the qualification ion

\begin{tabular}{|c|c|c|c|c|c|c|}
\hline Elution order & Standards & $\begin{array}{l}\text { Quantification } \\
\text { Ion }\end{array}$ & $\begin{array}{c}\text { Qualification } \\
\text { Ion }\end{array}$ & $\begin{array}{c}\mathrm{F} 1 \\
0.030 \mu \mathrm{g} \mathrm{L}^{-1}\end{array}$ & $\begin{array}{c}\mathrm{F} 2 \\
0.100 \mu \mathrm{g} \mathrm{L}^{-1}\end{array}$ & $\begin{array}{c}\mathrm{F} 3 \\
0.300 \mu \mathrm{g} \mathrm{L}^{-1}\end{array}$ \\
\hline 1 & 1,4-Dichlorobenzene-d4 (SS1) & 150 & 152 & 0 & 0 & 0 \\
\hline 2 & Naftalene-d8 (SS2) & 136 & 137 & 3 & 0 & -11 \\
\hline 3 & Acenaftene-d10 (SS3) & 162 & 164 & -4 & 0 & -1 \\
\hline 4 & Molinate & 126 & 187 & 44 & 3 & 2 \\
\hline 5 & Trifluraline & 306 & 264 & 5 & 0 & -2 \\
\hline 6 & Hexachlorobenzene & 284 & 286 & 4 & -2 & 0 \\
\hline 7 & Simazine & 201 & 186 & -8 & -2 & 1 \\
\hline 8 & Atrazine & 200 & 215 & -6 & -1 & 1 \\
\hline 9 & Lindane & 181 & 219 & -324 & -79 & -24 \\
\hline 10 & Antracene-d10 (SS4) & 188 & 189 & 0 & 0 & -1 \\
\hline 11 & Propanil & 161 & 163 & -4 & 3 & 3 \\
\hline 12 & Heptachlor & 272 & 274 & -3 & 0 & 0 \\
\hline 13 & Alachlor & 160 & 188 & -5 & 0 & 0 \\
\hline 14 & Aldrin & 263 & 261 & -1 & -1 & 2 \\
\hline 15 & Metolachlor & 162 & 238 & 4 & 2 & -1 \\
\hline 16 & Pendimethalin & 252 & 253 & -13 & -5 & -4 \\
\hline 17 & Heptachlor epoxide & 183 & 353 & 12 & -2 & 1 \\
\hline 18 & Chlordane I & 373 & 375 & 7 & -4 & 1 \\
\hline 19 & Chlordane II & 373 & 375 & 26 & -1 & -1 \\
\hline 20 & Chlordane III & 373 & 375 & 15 & -5 & -5 \\
\hline 21 & Endosulfan I & 195 & 241 & 4 & 0 & 4 \\
\hline 22 & 1,3-Diphenoxybenzene (IS) & 141 & 262 & - & - & - \\
\hline 23 & Endosulfan II & 195 & 241 & -3 & 2 & 1 \\
\hline 24 & Dieldrin & 79 & 277 & 18 & 4 & 5 \\
\hline 25 & Endrin & 263 & 261 & 2 & -2 & -1 \\
\hline 26 & DDT I & 235 & 165 & -16 & 4 & 1 \\
\hline 27 & DDT II & 235 & 165 & -7 & -1 & 1 \\
\hline 28 & Crisene-d12 (SS5) & 240 & 236 & 2 & -1 & -1 \\
\hline 29 & Methoxychlor & 227 & 228 & 0 & -2 & -1 \\
\hline 30 & Permethrin I & 183 & 163 & -76 & -4 & 1 \\
\hline 31 & Permethrin II & 183 & 163 & -29 & -7 & -3 \\
\hline 32 & Perilene-d12 (SS6) & 260 & 264 & 3 & 1 & 1 \\
\hline
\end{tabular}

SS = surrogate standard; IS = internal standard.

Table 2. Instrumental precision evaluated for 10 concentration levels $(n=7)$

\begin{tabular}{|c|c|c|c|c|c|c|c|c|c|c|c|c|c|c|c|c|c|c|c|c|c|c|c|c|c|c|c|}
\hline 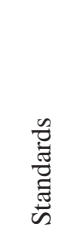 & 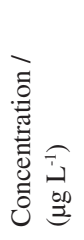 & 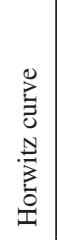 & $\begin{array}{l}\frac{\tilde{0}}{7} \\
\frac{0}{0} \\
\frac{\pi}{<}\end{array}$ & $\frac{\Xi}{\frac{E}{Z}}$ & $\frac{\Xi}{\frac{E}{0}}$ & 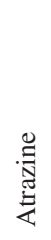 & 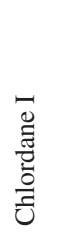 & 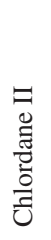 & 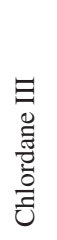 & $\overrightarrow{\widehat{\theta}}$ & $\begin{array}{l}= \\
\text { 它 } \\
\text { 年 }\end{array}$ & 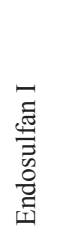 & 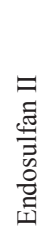 & $\begin{array}{l}\text { 吾 } \\
\text { 至 }\end{array}$ & 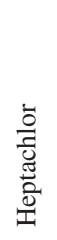 & 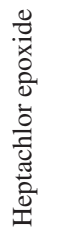 & 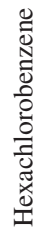 & $\begin{array}{l}\stackrel{\Xi}{\Xi} \\
. \Xi\end{array}$ & $\begin{array}{l}\frac{\tilde{0}}{0} \\
\frac{0}{0} \\
\frac{\pi}{0} \\
\frac{0}{0} \\
\sum\end{array}$ & 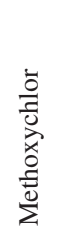 & 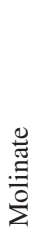 & 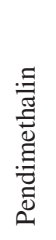 & 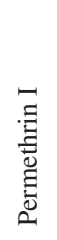 & 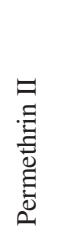 & $\begin{array}{l}\bar{\Xi} \\
\stackrel{\bar{Z}}{0} \\
\stackrel{0}{0}\end{array}$ & 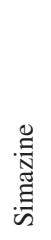 & 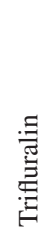 \\
\hline & & & \multicolumn{25}{|c|}{ Instrumental Precision-Relative Standard Deviation / (\%) } \\
\hline $\mathrm{P} 1$ & 1 & 22 & $\#$ & 12 & \# & \# & & & & & \# & & & & & $\#$ & 7 & 46 & 10 & \#\# & 8 & \#\# & \#\# & \#\# & \# & $\#$ & 16 \\
\hline $\mathrm{P} 2$ & 2.5 & 20 & 46 & 4 & 10 & 32 & 13 & 35 & 14 & & 6 & 4 & 21 & 11 & 44 & 4 & 6 & 16 & 4 & 9 & 5 & 24 & \#\# & \#\# & $\#$ & $\#$ & 9 \\
\hline P3 & 5 & 18 & 12 & 1 & 10 & 13 & 5 & 16 & 7 & 17 & 4 & 5 & 6 & 5 & 14 & 8 & 2 & 3 & 2 & 2 & 4 & 14 & 4 & 4 & 7 & 5 & 16 \\
\hline P4 & 10 & 16 & 10 & 4 & 9 & 4 & 4 & 8 & 6 & 18 & 6 & 9 & 9 & 2 & 5 & 8 & 5 & 5 & 7 & 8 & 6 & 9 & 12 & 16 & 9 & 9 & 7 \\
\hline P5 & 25 & 14 & 7 & 3 & 3 & 3 & 3 & 5 & 4 & 6 & 2 & 4 & 5 & 2 & 5 & 4 & 4 & 5 & 4 & 5 & 5 & 5 & 6 & 6 & 6 & 5 & 4 \\
\hline P6 & 50 & 12 & 1 & 3 & 4 & 1 & 3 & 3 & 6 & 5 & 4 & 1 & 2 & 1 & 4 & 3 & 4 & 3 & 2 & 7 & 5 & 2 & 9 & 11 & 4 & 4 & 4 \\
\hline P7 & 100 & 11 & 3 & 2 & 2 & 4 & 2 & 6 & 3 & 3 & 1 & 4 & 2 & 2 & 3 & 1 & 3 & 2 & 3 & 3 & 4 & 2 & 6 & 6 & 5 & 4 & 3 \\
\hline P8 & 250 & 10 & 3 & 7 & 3 & 3 & 2 & 3 & 3 & 8 & 2 & 1 & 1 & 2 & 3 & 2 & 3 & 2 & 2 & 4 & 4 & 1 & 7 & 7 & 5 & 3 & 4 \\
\hline P9 & 500 & 9 & 4 & 4 & 1 & 3 & 2 & 3 & 4 & 2 & 3 & 3 & 2 & 1 & 5 & 3 & 6 & 4 & 3 & 5 & 6 & 3 & 9 & 10 & 6 & 5 & 5 \\
\hline$\underline{\mathrm{P} 10}$ & 1000 & 8 & 6 & 3 & 2 & 3 & 2 & 1 & 2 & 5 & 2 & 3 & 1 & 1 & 4 & 2 & 3 & 3 & 5 & 5 & 4 & 4 & 11 & 11 & 4 & 5 & 6 \\
\hline
\end{tabular}


Table 3. Results for precision and accuracy for F1 $\left(0.030 \mu \mathrm{g} \mathrm{L}^{-1}\right)$ and F3 $\left(0.300 \mu \mathrm{g} \mathrm{L}^{-1}\right)$ fortification levels

\begin{tabular}{|c|c|c|c|c|c|c|c|c|}
\hline & \multicolumn{4}{|c|}{$\mathrm{F} 1$} & \multicolumn{4}{|c|}{ F3 } \\
\hline & \multicolumn{2}{|c|}{ Repeatability } & \multicolumn{2}{|c|}{ Intermediate precision } & \multicolumn{2}{|c|}{ Repeatability } & \multicolumn{2}{|c|}{ Intermediate precision } \\
\hline & $* \mathrm{R} \%$ & RSDr & $* \mathrm{R} \%$ & RSDpi & $* \mathrm{R} \%$ & RSDr & $* \mathrm{R} \%$ & RSDpi \\
\hline Molinate & 87 & 76 & 74 & 79 & 32 & 46 & 49 & 48 \\
\hline Trifluraline & 61 & 11 & 57 & 25 & 54 & 13 & 56 & 17 \\
\hline Hexachlorobenzene & 36 & 17 & 36 & 27 & 34 & 18 & 38 & 25 \\
\hline Simazine & 116 & 4 & 107 & 14 & 107 & 15 & 112 & 21 \\
\hline Atrazine & 114 & 5 & 107 & 11 & 110 & 14 & 112 & 17 \\
\hline Lindane & 72 & 4 & 72 & 8 & 72 & 11 & 71 & 18 \\
\hline Propanil & 114 & 9 & 117 & 20 & 121 & 14 & 137 & 24 \\
\hline Heptachlor & 57 & 4 & 52 & 22 & 53 & 12 & 49 & 18 \\
\hline Alaclor & 106 & 6 & 102 & 11 & 99 & 10 & 99 & 11 \\
\hline Aldrin & 17 & 14 & 25 & 32 & 50 & 22 & 43 & 33 \\
\hline Metolachlor & 114 & 3 & 114 & 9 & 112 & 9 & 111 & 11 \\
\hline Pendimethalin & 68 & 12 & 72 & 23 & 67 & 9 & 70 & 15 \\
\hline Heptachlor epoxide & 70 & 9 & 69 & 19 & 68 & 7 & 68 & 10 \\
\hline Chlordane & 61 & 22 & 58 & 40 & 58 & 13 & 60 & 28 \\
\hline Endosulfan & 79 & 9 & 82 & 22 & 80 & 6 & 80 & 8 \\
\hline Dieldrin & 81 & 12 & 84 & 25 & 73 & 7 & 74 & 9 \\
\hline Endrin & 80 & 8 & 80 & 18 & 79 & 5 & 82 & 6 \\
\hline DDT & 43 & 27 & 45 & 44 & 42 & 20 & 41 & 22 \\
\hline Methoxychlor & 85 & 19 & 82 & 36 & 71 & 13 & 74 & 14 \\
\hline Permethrin & 35 & 27 & 32 & 43 & 37 & 17 & 33 & 21 \\
\hline
\end{tabular}

*R\%: Recovery (\%).

limits of quantification at fortification level of $0.030 \mu \mathrm{g} \mathrm{L} \mathrm{L}^{-1}$. Table 4 shows the limits of quantification and the MRL values from Regulation MS 518/2004. The limits of quantification achieved with the proposed method are also adequate for the control of pesticide residues in drinking water in accordance to the European standard. ${ }^{21}$

The method developed was only incapable of adequately determining four of the pesticides from Regulation MS 518/2004: glyphosate and 2,4-D, which are not suitable for direct GC determination, and bentazone and pentachlorophenol, which presented sensitivity, but were not adequately recovered in the multiresidue extraction by SPE.

Method applicability in real samples and system suitability

Application of the method with real samples showed excellent performance in terms of system suitability. No pesticide was detected in the real samples evaluated.

At the concentration range between 0.030 and $0.300 \mu \mathrm{g} \mathrm{L}{ }^{-1}$, the lowest result obtained for coefficient of determination using the linear regression equation was 0.995. These results proved to be adequate for utilization
Table 4. Quantification limits of the proposed method and maximum residue limits established by Regulation MS 518/2004

\begin{tabular}{lcc}
\hline Pesticides & $\begin{array}{c}\text { Quantification limit / } \\
\left(\mu \mathrm{g} \mathrm{L}^{-1}\right)\end{array}$ & $\begin{array}{c}\text { MRL Regulation MS } \\
518 / 2004 /\left(\mu \mathrm{g} \mathrm{L}^{-1}\right)\end{array}$ \\
\hline Alachlor & 0.023 & 20.0 \\
Aldrin & 0.010 & 0.03 \\
Dieldrin & 0.023 & 0.03 \\
Atrazine & 0.035 & 2 \\
Chlordane & 0.015 & 0.2 \\
DDT & 0.010 & 2 \\
Endosulfan & 0.033 & 20 \\
Endrin & 0.033 & 0.6 \\
Heptachlor & 0.023 & 0.03 \\
Heptachlor epoxide & 0.033 & 0.03 \\
Hexachlorobenzene & 0.003 & 1 \\
Lindane & 0.010 & 2 \\
Metolachlor & 0.018 & 10 \\
Methoxichlor & 0.023 & 20 \\
Molinate & 0.018 & 6 \\
Pendimethalin & 0.093 & 20 \\
Permethrin & 0.018 & 20 \\
Propanil & 0.035 & 20 \\
Simazine & 0.053 & 2 \\
Trifluraline & 0.023 & \\
\hline & & 20 \\
\hline & & \\
\hline
\end{tabular}


in routine analysis for any type of water that meets physicochemical parameters for potability. Soboleva and Ambrus $^{22}$ make a good discussion on system suitability studies that combine parameters of injection and detection. The results obtained in our study are in accordance with those presented by these authors.

\section{Conclusions}

The present method was shown to be adequate for the determination of most pesticides in drinking water, thus meeting requirements in the Brazilian legislation. The GC-MS in the SIM mode proved to be essential for quantification with adequate sensitivity and selectivity for pesticide residues in samples from a number of origins and that present high turbidity, without significant interference. The chromatographic parameters showed excellent results in terms of efficiency, resolution and total analysis time. The method was utilized for over a year without presenting significant modifications in retention times. The preconcentration factor of 400 times of the SPE step was essential for reaching Regulation MS 518/2004 limits. In the method development, a large number of factors were considered which significantly increased sensitivity and robustness. In the evaluation of precision, the results were excellent for all concentration levels studied when compared with values given by the Horwitz curve. Intermediate precision was also considered adequate, showing no differences on different days. Recoveries were consistent, regardless of the day and concentration level. Although some analytes presented low recoveries, the consistency of the results obtained and the use of surrogate standards make it possible to reliably establish a correction factor for the analysis of these analytes in real samples.

\section{Acknowledgments}

The authors acknowledge the financial support and fellowships from the Brazilian agencies $\mathrm{CNPq}$ and CAPES.

\section{References}

1. Hamilton, D. J.; Ambrus, A.; Dieterle, M.; Felsot, A. S.; Harris, C. A.; Holland, P. T.; Katayama, A.; Kurihara, N.; Linders, J.; Unsworth, J.; Wong, S.-S.; Pure Appl. Chem. 2003, 75, 1123.
2. Brazil, Ministry of Health, Regulation MS n 518/2004, Available at: http://portal.saude.gov.br/portal/arquivos/pdf/ portaria_518_2004.pdf, accessed in October 2008.

3. Council Directive 98/83/EC of November 3, 1998 on the Quality of Water Intended for Human Consumption; Official Journal of the European Communities L 330, December 5, 1998, pp. 32-54.

4. Rissato, S. R.; Libânio, M.; Giafferis, G. P.; Gerenutti, M.; Quim. Nova 2004, 27, 739.

5. Brondi, S. H. G.; Spoljaric, F. C.; Lanças, F. M.; J. Sep. Sci. 2005, 28, 2243.

6. Lanchote, V. L.; Bonato, P. S.; Cerdeira, A. L.; Santos, N. A. G.; Carvalho, D.; Gomes, M. A.; Water, Air, Soil Pollut. 2000, $118,329$.

7. Dores, E. F. G. C.; Carbo, L.; Ribeiro, M. L.; De-LamonicaFreire, E. M.; J. Chromatogr. Sci. 2008, 46, 585.

8. Primel, E. G.; Zanella, R.; Kurz, M. H. S.; Gonçalves, F. F.; Machado, S. L. O.; Marchezan, E.; Quim. Nova 2005, 28, 605.

9. Wells, M. J. M. In Sample Preparation Techniques in Analytical Chemistry; Mitra, S., ed., Wiley-Interscience: Hoboken, NJ, USA, 2003, pp. 37-138.

10. Lanças, F. M.; Validação de Métodos Cromatográficos de Análise, Rima: São Carlos, 2004, p. 62.

11. Fernandez-Alba, A.; Chromatographic-Mass Spectrometric Food Analysis for Trace Determination of Pesticide Residue, Elsevier: Almeria, Spain, 2005, p. 487.

12. Huck, C. W.; Bonn, G. K.; J. Chromatogr., A 2000, 885, 51.

13. Pichon, V.; Charpak, M.; Henion, M. C.; J. Chromatogr., A 1998, 795, 83.

14. Reeve, R. N.; Introduction to Environmental Analysis, John Willey \& Sons: West Sussex, UK, 2002. pp. 78-104.

15. Ahmed, F. E.; Trends Anal. Chem. 2001, 20, 649.

16. Balinova, A.; J. Chromatogr., A 1996, 754, 125.

17. Currie, L. A.; Chemom. Intell. Lab. Syst. 1997, 37, 151.

18. Horwitz, W.; Validation: An Invisible Component of Measurement, AOAC International: Gaithersburg, USA, 2003. p.10.

19. Spurlock, F.; Burow, K.; Dubrovsky, N.; J. Environ. Qual. 2000, $29,474$.

20. CITAC/EURACHEM Guide; The Fitness for Purpose of Analytical Methods. A Laboratory Guide to Method Validation and Related Topics, LGC UK: Middlesex, UK, 1998, p. 43.

21. Caldas, S. S.; Demoliner, A.; Primel, E. G.; J. Braz. Chem. Soc. 2009, 20, 125.

22. Soboleva, E.; Ambrus, A.; J. Chromatogr., A 2004, 1027, 55.

Received: November 10, 2008 Web Release Date: April 17, 2009 